\title{
Towards More Sophisticated Academic Writing: Moving Beyond the Five-Paragraph Essay
}

\author{
Ditthayanan Punyaratabandhu \\ Mahidol University International College, Thailand \\ Edward Rush \\ Mahidol University International College, Thailand \\ Michael J. Kleindl \\ International Christian University, Japan \\ Paul Wadden \\ International Christian University, Japan
}

\begin{abstract}
This article argues that due to test washback, simplicity of instruction, misconceptions of Western-heritage teachers about Asian students, and prevalence in ESL textbooks, the conventional five-paragraph essay is the dominant writing form taught to Asian university students. Yet as Dombek and Herndon (2004) observe, such a simplified form does not reflect the "periodic development" commonly found in the essays of proficient English-language writers and expected in Western university courses. To address this shortcoming, two sophisticated teaching methodologies used in language and liberal arts programs in Thailand and Japan are presented: the essay based upon periodic rather than cumulative development, and the Situation-ProblemSolution-Evaluation (SPSE) approach. Such pedagogies, it is argued, challenge students to move beyond formulas, to incorporate and integrate sources (in addition to personal experience), to engage in critical and creative analysis, and to enact a richer process of thinking in their writing.
\end{abstract}

\section{The Orthodoxy of the Five-Paragraph Essay}

In a compilation of critical perspectives on language instruction in TESOL Quarterly in 1999, Alastair Pennycook observed that work in TESOL had for a long time been "too narrowly constructed to be of much interest to people outside the area" (p. 346). In other words, the instrumentalist assumptions that underlie much of the field seem to have been accepted to degree that analysis rarely occurred in the discipline. This rigidity continues to be illustrated in the widespread use - and misuse - of the "five-paragraph essay." Any student who has been required to take an English proficiency examination, such as the TOEFL or IELTS, will have been taught this familiar several-paragraph thesis-driven form (typically five paragraphs, but 
ranging from three to six). Driven by test washback (the back-to-front influence tests have on teaching and learning) and its ease of instruction, this model has become the norm in ESL courses and texts around the world. However, authentic writing by authors fully proficient in English rarely takes this form. Instead, as Dombek and Herndon observed,

professional essayists tend to write ... in the periodic style, leading up to the most important thought . . . in their final sentences. They do this because their ideas are so complex or counterintuitive that they could not be understood without the train of thought and pieces of evidence that precede them $(2004, p$. 27).

As Dombek and Herndon pointed out, while the five-paragraph essay can serve as a good base for beginners, it is often inappropriate for higher-level writing. Thus, this paper will suggest and evaluate teaching methodologies which can be used to help students move beyond familiar formulas and challenge them to employ more sophisticated writing styles and rhetorical forms to better engage in the kinds of critical and creative analysis common in authentic discourse.

The authors of this paper teach at two institutions. One is the Preparation Center (PC) for Languages and Mathematics, a pre-university program for Mahidol University International College (MUIC) in Thailand; the other is the English for Liberal Arts Program (ELA) at International Christian University (ICU) in Japan. Both programs are considered to be elite within their respective domains, and the English language skills of their students are generally higher than their peers in comparable universities. The common aim of these programs is to produce graduates who not only can use English to communicate functionally to complete basic academic tasks, but who also can use their language abilities critically and creatively. It is for these reasons that teachers in both programs have sought to introduce approaches to writing which move beyond the five-paragraph orthodoxy. To understand how these approaches can be used successfully, it is first necessary to understand why they are needed.

\section{Literature Review}

\section{Situation}

Recent data produced by Educational Testing Service (ETS) show that Thai speakers rank 85th out of 113 national language groupings on performance on the TOEFL-iBT, while the Japanese rank $102^{\text {nd }}$ (Educational Testing Service, 2011). However, data suggest that Japanese have developed better critical thinking skills than Thais. A comparative survey of the capacity of 15 year-old students to integrate, interpret, reflect on, and evaluate material contained in reading texts shows Thais ranked $52^{\text {nd }}$ out of 65 countries in the Organisation for Economic Cooperation and Development (OECD), while the Japanese ranked $8^{\text {th }}$ (Organisation for Economic Co-operation and Development, 2010). Therefore, though the linguistic challenges facing students in both countries are similar, the task of improving thinking skills in Thailand appears more formidable. The position of this paper is that the conventional approach to ESL writing is largely unsuitable for cultivating higher-order thinking skills.

As stated before, the unsatisfactory orthodoxy in writing instruction stems largely from the washback effect of standardized testing. This concern has been raised for many years. Writing in 1991, Raimes referred to the "formulaic essay writing and assembly line grading of ETS's [then] Advanced Placement [AP] Essay" (Vopat, cited in Raimes, p. 439). She further observed that it is doubtful whether standardized tests such as the AP Essay "recognize[d] a wider variety of rhetorical modes" than the ethnocentric deductive linear argument (Raimes, 1991, p. 439). She concluded that language instructors "should avoid recommending and using reductive methods of instruction and materials for test preparation" and that "students should be spending 
time learning English, not learning ETS coping skills." Nevertheless, almost all universities whose language of instruction is English still require non-native students to pass some sort of standardized English proficiency examination, preparation for which usually involves reductive coaching techniques and simplified writing forms.

The most commonly accepted proficiency standards are the TOEFL and IELTS tests. A student's performance on such tests often determines whether the applicant is accepted or rejected. Yet with such high-stakes tests, there are tricks and strategies which can be employed in order to raise test-takers' scores. Qi (2007) emphasized the effect of such tests on writing instruction when she stated "teachers and students [focus] only on the aspects of writing that they [believe] would help to achieve higher test scores, while completely ignoring the need to be able to write communicatively in real-life situations" (p. 65). To clarify, emphasis is placed on producing a clean piece of writing which follows set formulas and is easily graded. As a consequence, students are not pushed into the higher levels of thinking: analysis, synthesis, evaluation as in Bloom's taxonomy (Bloom, Engelhart, Furst, Hill, \& Krathwohl, 1956). Instead, they are tested on their recall and application of set patterns and models (Cheng, Rogers, \& Hu, 2004; HampLyons, 1997; Raimes, 1990).

\section{Problems}

One problem with this approach is that students become more focused on "getting it right" (Blanton, 1987) than becoming skilled writers. Writing, especially for lower-level students, thus becomes a chore which is often approached with fear or boredom (Blanton, 1987). When writing is attempted, it tends to be formulaic (Vopat, cited in Raimes, 1990). Popular textbooks, whether for classroom instruction or exam preparation, often design topics to fit the fiveparagraph essay structure. These topics generally present students with a choice which they must support using their own knowledge and experience, and because there is often no input resource from which students can draw to support their ideas, their topic development is limited to the extent of their personal experience. The result, as the authors and other professional writing teachers have observed, is essays written mechanically, "following the guidelines" of the standard five-paragraph format often consisting of claims or ideas supported minimally through limited knowledge of the topic (Dombeck \& Herndon, 2004, p. 10).

Another problem stems from misconceptions of Western-heritage teachers about Asian learning styles and capacities. As Biggs has suggested, most Western-heritage teachers never seriously examine their assumptions that all Asian classrooms are "highly authoritarian; [use] teaching methods [that] are mostly expository, [and are] sharply focused on preparation for external examinations" (1996, p. 46). This leads to beliefs that Asian students will nearly always show a preference for "low cognitive level learning strategies" associated with poor learning outcomes (Biggs, 1996, p. 46). In other words, Western teachers often assume that Asian students do not want - or are unable - to think critically and instead benefit more from mastering set patterns in order to pass exams. Several studies have shown, in fact, that as a result of their preconceptions of ESL students, teachers often give feedback to L2 writers which focuses more on grammar and structure errors than on content (Ferris, Brown, Liu, \& Stine, 2011; Matsuda \& Matsuda, 2010).

\section{Strategies for a Solution}

\section{Methodology}

Two strategies have been used by the authors of this paper to try to move beyond the simple prescription of the five-paragraph essay. Both approaches introduce students to a different way of thinking about their ideas. At ICU, some advanced writing classes now focus on developing periodic writing. The essays written in these classes look drastically different from typical ESL 
essays. Whereas the five-paragraph essay is thesis-driven and displays what Dombek and Herndon (2004, p. 26-27) termed "cumulative development," these essays are content-driven and display "periodic development." At MUIC, the Situation-Problem-Solution-Evaluation (SPSE) approach advocated by Hamp-Lyons and Heasley (2006) has been introduced to preuniversity students. Each approach is explained in more detail in the following sections.

Cumulative vs. periodic development. This approach is employed by select teachers at ICU to teach upper-intermediate to advanced-level students with TOEFL ITP scores of 550 and higher. The course is a reading and writing class, and instruction is delivered via 3 classroom and 2 tutorial hours per week for 10 weeks. The students are first-year Japanese university students yet to declare a major. In addition to requiring students to write a traditional five-paragraph style persuasive essay based upon cumulative rhetoric, the course introduces students to periodic development in essays that draw upon this more sophisticated rhetorical pattern (Dombek \& Herndon, 2004).

In traditional five-paragraph essays that follow cumulative development, the essay writer presents a thesis statement in the first paragraph, followed by paragraphs in which each opening sentence describes the topic of the paragraph, often referring directly back to the thesis statement; the essay ends with a conclusion which sums up the ideas presented in the essay and restates the thesis. While cumulative development may be appropriate for English proficiency examinations, this style of writing - as Dombek and Herndon (2004) have argued tends to produce essays where topic development is simplistic and one-dimensional.

In contrast, sophisticated readers of English (including university professors) expect more complex forms of writing. Thus, in the ELA of ICU, some teachers introduce students to essay writing that uses periodic development. Under this approach, sentences at the beginning of the paragraph drive ideas forward and are used to link reasoning between paragraphs (Appendix A shows a visual representation of the rhetorical structure of periodic development in contrast to that of cumulative development). Furthermore, the thesis is often not presented until the conclusion of the essay, after the supporting ideas have been developed and elaborated upon. It can be argued that this approach is more authentic as it allows students to display their thinking process and, because ideas are explored as they arise, does not limit students to one idea from the very beginning. Thus, oftentimes student writers will discover that by the end of the essay they have moved from answering a simple question to asking (and answering) much more complex questions because they have been able to examine different aspects of the topic.

The differences in how students think about the topic are usually reflected in the transition words used in the essays. With cumulative development, transition words generally reflect linear thinking (e.g., First, Second, Third, In addition, For example), whereas with periodic development, they tend to reflect progressive thinking (e.g., This being the case, Considering this, If so). The end result is an essay where students have analyzed and evaluated several different aspects of a topic and have a formed a conclusion based on information and analysis which has not been manipulated to fit a pre-set idea. See Appendix B for a model of a periodic essay and Appendix $C$ for an example of a student essay using this approach.

SPSE. MUIC PC started using the SPSE approach recently in their highest-level class in which students study writing 8 hours a week for 10 weeks. Students at this stage are at the intermediate level, most having entered the program at the lower-intermediate level, with TOEFL ITP scores between 420 and 530. For this approach, essays are referenced from input texts and lectures provided by teachers and from the student's own research. 
To reiterate, SPSE stands for Situation-Problem-Solution-Evaluation. Firstly, students discuss the situation or background of the topic. This can include facts, current news, and different viewpoints related to the subject. Students then consider the problems associated with the issue, such as controversies or negative effects. From there, students are either asked to suggest solutions to the problem or explain solutions presented in the input sources. Finally, students evaluate the solutions. Evaluation includes not only an assessment of how effective the solution is, but also how ethical it is.

As the aim is to encourage integration of skills, essay topics are centered on a single theme which the students study all term. Thus, the students do not compose based on their own limited experience but instead are required to use information from several sources, including websites, books, adapted texts, and lectures. They are taught the Cornell University note-taking system, which has been shown to improve understanding and recall through the use of critical thinking questions and summary writing (Pauk \& Owens, 2005). Students are also introduced to basic logical fallacies and ethical frameworks so they have a foundation on which to assess and evaluate information. To illustrate, a theme used at the MUIC PC in 2012 related to Jared Diamond's theory of social collapse. Students took notes of the material in the book during the term and were introduced to some of the more basic logical fallacies (e.g., "slippery slope" and "excluded middle") as an aid to critical analysis. Their final assessment task, after formative development, was to use notes they took of a lecture and reading on a related topic to write a fully referenced essay under exam conditions. They were given an opportunity to develop their ideas in a 25-minute group discussion. The assessment process was designed to move the students towards higher-level cognitive skills. Thus, after demonstrating understanding of the reading and lecture through their summary notes, the students were required to analyze and synthesize the arguments in their written responses, before evaluating the arguments using logical analysis in the final discussion. Appendix D presents a description of a particular SPSE task and a sample student response.

\section{Process Writing}

In both the MUIC PC and the ICU ELA programs, students follow a writing process consisting of planning, writing, and editing. Prior to writing, they produce a plan which they will use as an initial guide for their composing. Students then write several drafts edited first by themselves, then by their peers, and then by their teacher before a final draft is submitted for grading. In both programs, editing focuses mainly on content and organization, and, to a lesser extent, grammar. Thus, students not only make corrections to their essays but must also explain their errors and their corrections. In this way, students reflect on both the content and the technical aspects of essay writing.

\section{Assessment}

In ICU's ELA, the students' writing is assessed through graded drafts and a series of one-to-one writing tutorials with the teacher during which the student can ask for advice or clarification, describe intentions or problems, and receive direct teacher feedback on their writing. Many teachers use rubrics to give students feedback, such as the ICU Writing Rubric illustrated in Appendix E, which includes the criteria of Content (critical / creative thinking), Organization, and Language Control and Convention.

At MUIC PC, writing is assessed in three ways. Firstly, class essays are graded. Students spend two to three weeks on each essay and experience the entire writing process with peer comments and teacher guidance. Secondly, as mentioned previously, at the end of the term, they take an integrated exam. This starts with a 30-minute lecture and a 750-word reading over a 2-hour period. Students are then given 2 hours to write a response essay on the topic, 
referencing the inputs they were provided with. Thirdly, students take part in a 30-minute videotaped discussion related to the topic.

\section{Discussion}

In both cases, writing using periodic development is encouraged. However, as the students in the Thai program are often of a lower skill level than those in the Japanese program, they require a more guided approach in their writing. Thus, SPSE provides a framework for them to elaborate their thinking.

Writing produced by students using these two approaches displays more sophisticated thinking than that which results from the five-paragraph model. Writers are able to move beyond the narrow context provided in a typical opinion essay topic and examine a much broader range of views. Since the focus is not on finding reasons to support the initial thesis, but rather on investigating and exploring different relevant ideas and then drawing a conclusion, students are able to - and in fact, must - ask more questions and gather information. In such writing, students often end up challenging the initial assumptions of the topic instead of simply accepting the choices they have been given. Accordingly, their writing shows evidence of the analysis, synthesis, and evaluation taxonomized as higher-order thinking skills (Bloom et al., 1956).

By providing students with input resources (texts and lectures), the writing task becomes easier and more difficult at the same time. Students are relieved of the burden of trying to tap their limited knowledge relevant to the topic, but they must learn to utilize several additional skills such as note-taking and listening to analyze and evaluate information they have been given. This is a more authentic writing task than a traditional five-paragraph essay as it provides students with practice for university classes where professors will give readings and lectures and ask students to hand in a written response or compose research-based essays or reports. The writing task becomes much more integrated, in line with the goals of a liberal education. Moreover, students begin to realize that writing does not happen in a vacuum; their topics and their ideas have real-world relevance.

In general, periodic development challenges students to think more deeply about the topic and information they have been given. Because this type of development requires students to connect their ideas forward-going more deeply into one idea or moving on to a new, expanded idea-they are pushed towards higher-order thinking skills resulting in more complex thought processes. This process of increased sophistication can be seen in the model essay in Appendix B, "The Myth of Uniqueness," in which O-Young Lee poses and answers strategic questions, quotes leading scholars, and debunks their statements to arrive at a conclusion, which his analysis logically builds toward but which is not apparent at first. It is also illustrated in the student essay on Muslim headscarves in France in Appendix C, in which the writer uses logic and analysis to unwrap the complexity of the issues, rather than taking a for-or-against position at the outset. Writing produced through periodic development, as these two essays suggest, becomes more interesting for both the teacher and the student and is more personal than writing in a five-paragraph essay based merely on private experience because students must examine, question, and sometimes revise their beliefs and assumptions. When students understand that essay writing involves more than just fulfilling a set pattern, they begin to see that differing essays can be written on the same topic. The most obvious consequence of this is that they stop trying to be "right" and start trying to be "good." They realize that they can be different from their peers and those differences are what will potentially make their work outstanding. 
One problem the authors still face is grammatical accuracy, especially in lower-level preuniversity programs. The elimination of set patterns and models and the introduction of complex inputs mean that students are challenged on a much higher cognitive level. Under time constraints, such as essay exams, students tend to produce writing which displays more sophisticated thinking but less grammatical accuracy. More research needs to be done to find the balance between teaching grammar and teaching critical thinking.

\section{Conclusion}

Based on the experiences of the authors in both programs, a few practical recommendations can be made.

1. Periodic development should be introduced to intermediate and advanced writing classes to encourage more authentic and complex forms of writing.

2. Lower-level classes may find it useful to employ the SPSE approach as a framework for students who may find this type of thinking challenging.

3. Additional skills, such as logic, ethics, and referencing, should be taught to enhance students' ability to analyze and evaluate information.

4. Writing tasks should be integrated with other skills, and such integration should be reflected in the assessment.

5. Teachers should encourage self-reflection throughout the writing experience.

While the cumulative development form used in the conventional five-paragraph essay may serve as a good starting point for beginning writers, it should be just that - a starting point. Writing instruction should aim to produce writers who are able to critically examine a wide range of topics and employ a variety of forms to express more complex thinking. Periodic development, through the SPSE approach initially and then independently, can challenge students and foster the higher-order thinking and writing skills necessary to produce the sophisticated and authentic writing required at the university level and beyond.

\section{Author Note}

Ditthayanan Punyaratabandhu and Edward Rush, Mahidol University International College, Thailand, and Paul Wadden and Michael Kleindl, International Christian University, Japan.

This article is based upon the paper "Towards More Sophisticated Essay Writing: Going Beyond Pre-Fabricated Forms" delivered to the 8th Annual CamTESOL Conference at the National Institute of Education, Phnom Penh, February 25, 2012.

Correspondence concerning this article should be addressed to Ditthayanan Punyaratabandhu and Edward Rush, Preparation Center for Languages and Mathematics, Mahidol University International College, Salaya, Nakhon Pathom 73170 Thailand, and Paul Wadden and Michael Kleindl, English for Liberal Arts Program, International Christian University, 3-10-2 Osawa, Mitaka, Tokyo 181-0085 Japan. E-mail: Ditthayanan Punyaratabandhu, dithayap@gmail.com; Edward Rush, elwrush@gmail.com; Michael Kleindl, mkleindl@gmail.com; Paul Wadden, waddenpaul@gmail.com. 


\section{References}

Biggs, J. (1996). Western misperceptions of the Confucian-Heritage learning culture. In D. Watkins \& J. Biggs (Eds.), The Chinese learner: cultural, psychological, and contextual influences. (pp. 45-67). Comparative Education Research Centre: Hong Kong.

Blanton, L. L. (1987). Reshaping ESL students' perceptions of writing. ELT Journal, 41(2), $112-$ 118. http://dx.doi.org/10.1093/elt/41.2.112

Bloom, B. S., Engelhart, M. D., Furst, E. J., Hill, W. H., \& Krathwohl, D. R. (1956). Taxonomy of educational objectives: the classification of educational goals; Handbook I: Cognitive Domain. New York, NY: Longmans Green.

Cheng, L., Rogers, T., \& Hu, H. (2004). ESL/EFL instructors' classroom assessment practices: Purposes, methods, and procedures. Language Testing, 21(3), 360-389. http://dx.doi.org/10.1191/0265532204lt288oa

Dombek, K. K., \& Herndon, S. (2004). Critical passages: Teaching the transition to college composition. New York, NY: Teachers College Press.

Educational Testing Service. (2011). Test and score data summary for TOEFL@ internet-based and paper-based tests. Test and Score Data: Test of English as a Foreign Language. Princeton, NJ: Educational Testing Service. Available at http://www.ets.org/Media/Research/pdf/TOEFL-SUM-2010.pdf

Ferris, D., Brown, J., Liu, H., \& Stine, M. E. (2011). Responding to L2 students in college writing classes: Teacher perspectives. TESOL Quarterly, 45(2), 207-234. http://dx.doi.org/10.5054/tq.2011.247706

Hamp-Lyons, L. (1997). Washback, impact and validity: Ethical concerns. Language Testing, 14(3), 295-303. http://dx.doi.org/10.1177/026553229701400306

Hamp-Lyons, L., \& Heasley, B. (2006). The whole academic text. Study writing: A course in writing for academic purposes (p. 119-133). Cambridge, England: Cambridge University Press.

Matsuda, A., \& Matsuda, P. K. (2010). World Englishes and the teaching of writing. TESOL Quarterly, 44(2), 369-374, http://dx.doi.org/10.5054/tq.2010.22222

Organisation for Economic Co-operation and Development. (2010). PISA 2009 results. Paris, France: OECD.

Pauk, W., \& Owens, R. J. Q. (2005). How to study in college. Boston, MA: Wadsworth, Cengage Learning.

Pennycook, A. (1999). Introduction: Critical approaches to TESOL. TESOL Quarterly, 33(3), 329-348. http://dx.doi.org/10.2307/3587668

Qi, L. (2007). Is testing an efficient agent for pedagogical change? Examining the intended washback of the writing task in a high-stakes English test in China. Assessment in Education: Principles, Policy \& Practice, 14(1), 51-74.

http://dx.doi.org/10.1080/09695940701272856

Raimes, A. (1990). The TOEFL test of written English: Causes for concern. TESOL Quarterly, 24(3), 427-442. http://dx.doi.org/10.2307/3587228

Raimes, A. (1991). Out of the woods: Emerging traditions in the teaching of writing. TESOL Quarterly, 25(3), 407-430. http://dx.doi.org/10.2307/3586978 


\section{Appendix A}

Visual Representations of Rhetorical Structure Underlying Cumulative and Periodic Approaches to Writing

(from Dombek \& Herndon 2004, p. 28-29)

\begin{tabular}{|c|c|}
\hline Cumulative Approach & Periodic Approach \\
\hline $\begin{array}{c}\text { Figure 2.1 Structure of the Thesis/Supporting } \\
\text { Point Essay }\end{array}$ & $\begin{array}{r}\text { Figure 2.2 Structure of the Periodic Essay } \\
\text { with Subordinate Modification }\end{array}$ \\
\hline
\end{tabular}




\section{Appendix B \\ Model of a Periodic Essay Used at International Christian University, Tokyo The Myth of Uniqueness by O-Young Lee*}

Many of the countless books that have been written about Japan have been showy, like French fashion magazines, and popular because of that. Since the end of the war alone, there have been innumerable interpretive works written about Japan. Some of them, such as Ruth Benedict's The Chrysanthemum and the Sword, The Anatomy of Dependence by Doi Takeo, and Japanese Society by Nakane Chie, have contributed new words to the popular vocabulary. Others, particularly Japanese books, have taken their titles from such phrases already in popular use as "economic animal" and "Japan Inc." In Japan these interpretations of Japanese society inevitably become best sellers, and large numbers of people pick up the jargon in them just as they would pick up and carry the portable shrine at a local festival. Such jargon appears in newspaper headlines, in magazine editorials, in talks given by television and radio commentators. In the hands of writers with more artistic inclinations, this vocabulary that began in the halls of academia end up as words to a popular ballad. This festival of interpretations makes it all but impossible to see the real, the naked Japan with one's own eyes. Before one knows it, that naked Japan is dressed in illusory clothing by the masses and pop culture. That is why I decided here to examine Japanese culture through the eyes of an elementary school child.

Why should it be that interpretations of Japan, whether they be by Japanese or Westerners, are cloaked in this illusory clothing? And what is the nature of the child's vision that could expose this cover-up? The Anatomy of Dependence, one of the most widely known interpretations of Japan, provides some clues. It is typical of the genre. I am particularly interested in this book, not so much because of its content but because of its attempt to discover what is unique about the Japanese psychology and because of the way its author, Doi Takeo, makes his case.

Doi states his methodology quite clearly: "If there is anything unique about the Japanese psychology it must be closely related with the uniqueness of the Japanese language." And Doi hits upon the concept of amae (dependence) and is convinced of "the uniqueness of the word amae as an item of vocabulary in Japanese." But is "dependence" as Doi defines it peculiar to the Japanese language? For if it is not, his whole argument goes up in smoke. And indeed, it is not.

The fact is that in Japan's nearest neighbor the concept of "dependence" is as common as pebbles scattered by the roadside. In Korean, there are two equivalent terms for the Japanese word amae: origwan and unsok. Both are an integral part of daily speech. Not only are there equivalent words, but the concept of dependence plays such a crucial role in child rearing in Korea that one could say dependence is even more inextricably bound up with the Korean psyche than it is with the Japanese. Such Korean words as omsal, used to gain the sympathy of others by exaggerating one's pain and suffering, are far more complex than the simple Japanese term amae.

This being the case, why did a learned scholar like Professor Doi make such a grave error by asserting that the concept of dependence as expressed by the term amae is peculiar to Japan? The problem is not Professor Doi's alone. His argument is merely the product of a sense of separateness from the rest of Asia, a feeling that the Japanese have entertained ever since the Meiji Restoration of 1868. Professor Doi relates that what convinced him amae was a word peculiar to the Japanese language was a conversation he once had with a British woman who spoke fluent Japanese. She was talking in English about her child's infant years but suddenly 
switched to Japanese to say, "Kono ko wa amari amaemasen deshita" (we were not especially indulgent with this child). When Professor Doi asked why she had used Japanese only for that one sentence, she replied there was no way to say such a thing in English.

From this Doi adduces that amae is a word unique to the Japanese language. It is a strange leap of logic, and it is an indication of just how deeply the Japanese have come to believe, since the Meiji Restoration, that English is the language of the West, and even all the rest of the world. How else could Doi have been led to believe that if a Japanese word does not exist in equivalent form in English it must be peculiar to Japanese? Perhaps this is the key to the "illusory clothes" that cloak Japan and interpretations of Japan.

This sort of premise, that if it does not exist in English it must be peculiar to Japanese, is not uncommon. Many interpretations of Japan written by Japanese revolve around just such simple Japan versus Britain / America comparisons. Even those works that take a somewhat wider view broaden only one side of the equation, substituting Westerners for British and Americans. Although we can imagine Doi substituting a French or German mother in his story, would he have ever considered a Korean woman? Yet if one is trying to find out whether or not amae is a uniquely Japanese concept it seems that a normal first step would be to look at a language such as Korean, which has a much closer linguistic relationship to Japanese than do any of the European languages.

This reluctance among Japanese writers to "look East" is far from uncommon. As a result, they often call something uniquely Japanese when it would be more relevant to call it common to Japan and Korea, or to all of East Asia. We need not go far to find examples. The popular historian Higuchi Kiyosuke has written, "Among the civilized countries of the world Japan is the only one where seaweed is eaten." But he has apparently forgotten that Korea is a major producer and consumer of seaweed. In the book Nihonjin no Kokoro (The Spirit of the Japanese) by Umesao Tadao and four other Japanese scholars, it is boldly asserted: "The realization that night soil, human excrement, could be used as an organic fertilizer for vegetables was an amazing discovery." Umesao and his fellow authors conclude that it was originally a Japanese idea, failing to recognize that other people have long made use of this "high-level agricultural technology" (to use their own words). Anyone could tell after a few minutes in a Korean village that this wonderful organic technology is hardly unique to Japan. This is the same kind of short-cut logic we find in the amae argument: if it does not exist in the West, it must be peculiar to Japan. I have no desire to enter into a debate here on Japan's claim to the dubious distinction of a monopoly on amae, much less night soil. Nor do I seek to refute the work of these scholars. What I wish to point out is that sometimes popular books interpreting Japan, be they by Japanese or foreigners, wrap Japanese society in illusory clothing that bears little relation to reality. And this is usually because the basis of such books is a comparison only between Japan and the West.

The counterpoint to Western culture is not simply Japanese culture. Asian culture, although it does include Japan, is not defined merely by the experience of that one people. Characteristics of European culture must be seen in relation to all of Asia, not just Japan. For if we compare Japan only to the West, we run the risk of jumping to the mistaken conclusion that something is peculiar to Japan when in fact it might well be common to the entire Northeast Asian cultural sphere.

*Excerpt from The Compact Culture: The Japanese Tradition of "Smaller is Better." Tokyo: Kodansha International, 1984, pages 10-13. O-Young Lee, a prominent Korean writer and literary scholar, served as his nation's first Minister of Culture. 


\section{Appendix C \\ Student Essay in Periodic Form}

\section{Moslem Headscarves: \\ The Veiled Reality Behind the Islamic Dress and Western Society}

On September 2, 2004, a law banning students' displaying of religious symbols in French public schools came into effect. It forbid the wearing of ostensible religious apparel such as the Islamic veil, the Jewish Kippah and large Christian crosses (Jones). The French government had been debating the issue for nearly two decades, and it had intensified over the years with dozens of Muslim girls being expelled from secular schools for refusing to remove their headscarves on school grounds (Rhodes).

The government had claimed that there were several reasons to bring this law into effect. They insisted that wearing headscarves in schools showed submission to men and symbolized the inferior status of women, and the new law was significant because it encouraged Muslim women to be treated as equals to men in their French-Muslim culture. The change was also vital in that it protected the 1905 law of separation of church and state, known as laicite. France was sending a strong message to the world that they were maintaining a solid secular state with the new law that protected the laicite and stopped the human rights abuse of Muslim women (Benhold).

The issue would be settled by now if this was the end to the story. However, this scarf issue, or l'affaire du voile, is a lot more complicated than it may appear.

First of all, do women really feel that the headscarf is a sign of oppression? IslamiCity, one of the world's largest online sources of Islamic information, addresses how Islamic garments such as the veil are not a symbol of oppression, but rather a sign of self-respect and social status. The French government also announced in 2002 that out of 1.8 million French Muslim school girls, only around 2000 of them wore their headscarf to school. Moreover, only 157 girls refused to remove their headscarf when asked to do so (Taheri). The article and research manifest a misunderstanding of the symbolism of Islamic dresses by the French government and further shows that in reality, many woman are not being forced but have the choice to wear Islamic clothing.

If so, are Muslim headscarves not a symbol of human rights violation? Facts by IslamiCity and the French government suggest that perhaps the answer is, "Yes." But when it comes to the new law, the answer is much different. For the individuals that consider the veil to be a symbol of belonging to the Muslim community, the new law is an oppressing law that deprives them of their freedom of expression. London Member of the European Parliament Human Rights and Civil Liberties Committee Jean Lambert criticizes the law that "[banning] the wearing of religious symbols is a clear human rights violation" (Meade). Although the French government explains that one of the central aims of the new law is to save women's human rights, without any clear evidence, the law has much more power to violate human rights than it does to save it.

With that said, it is reasonable to state that the case here is not just about religious symbols in school, or about maintaining secularism in France or any European state-it is about whether Muslims have a place and a right in a Westernized society. And judging from the direction that this debate is headed, many Western societies seem to be moving toward even greater marginalization of Muslims in their country. A study by the International Helsinki 
Federation for Human Rights (IHF) states that in $11 \mathrm{EU}$ member states, Muslims have faced increased discrimination since the September 11 attacks and that there are widespread negative attitudes toward Muslims. For example in Germany, more than $80 \%$ of those surveyed answered that the word "Islam" is related to "terrorists" and "oppression of women." IHF also claims that the debate over the adoption of the French law banning ostensible religious attire in schools helped to encourage discrimination against Muslim women wearing headscarves across Europe. They see a rise in the anti Muslim sentiment known as Islamophobia, and that such attitude is salient in recent politics (Rhodes).

However, prohibiting Islamic attire for the mere fact that Islamic values are incompatible with Western values will not lead to mutual understanding and will only lead to a closed society without a place for Muslims to fit in. Western societies need to allow religious attire in public schools so that children can have a better understanding of non-Western values such as Islam and so that non-Western people living in Western societies will come to receive greater respect. If European societies start banning the headscarf at school, children in Europe might start perceiving the scarf as something immoral. It has the power to implant a negative image of Islamic clothing that would very easily lead to a negative image of Islam in general. National Council for the Social Studies (NCSS) insists that "knowledge about religions is not only a characteristic of an educated person, but it is also absolutely necessary for understanding and living in a world of diversity" (Study About Religions), and it would certainly not hurt to know that there are many ways to express those beliefs, which will help children adapt better to different values.

The culmination of this debate will be a decisive moment for the Muslims living in Western societies. Even though it may be better for countries to prohibit ostensible religious apparel in some cases where clear evidence shows violation of health or human rights, generally speaking, it is crucial for Western societies to allow conspicuous religious attire to be worn in school and to allow Islam to integrate into the Western world. The new law violates the freedom of expression, and it is wrong to justify the violation of human rights by concluding that Islamic veils are a symbol of oppression of women when there is no clear evidence. The governments' answers will tell Muslims if they will be allowed to be who they are, or if they need to be "Westernized Muslims"—-that is, Muslims without freedom of expression of their religious belief.

\section{Works Cited}

Benhold, Katrin, "French Muslims find haven in public schools." The New York Times. 29 September, 2008.

(http://www.nytimes.com/2008/09/30/world/europe/30schools.html?pagewanted=I\&_r=l)

"Head covering and the freedom of religion." IslamiCity; 2 October 2008. (http://www.islamicity.com/Articles/Articles.asp ? ref=IC0301-2 I78)

Jones, Elizabeth. "Muslim girls unveil their fears." BBC News. 28 March 2005. (http://news.bbc.co.uk/1/hi/programmes/this_world/4352171.stm)

Meade, Geoff. "French headscarf ban 'breaches human rights'." PA News. 23 September 2004. (http://www.nriinternet.com/EUROPE/BANon TURBAN/092304.htm)

Rhodes, Aaron. "Anti-Muslim bias 'spreads' in EU." BBC News. 7 May 2005 (http://news.bbc.co.uk/1/hi/world/europe/4325225.stm)

"Study about religions in the social studies curriculum." National Council for the Social Studies (http://www.socialstudies.org/resources/moments)

Taheri, Amir. "Viewpoints: Europe and the headscarf." BBC News. 10 February 2004. (http://news.bbc.co.uk/1/hi/world/europe/3459963.stm) 


\section{Appendix D \\ SPSE Response to Integrated Task Question at MUIC PC, Thailand}

This task was set for students preparing to enter Mahidol University International College. The entry standard is set at IELTS 5.5-6 or equivalent. The national average for all Thai students - at high school, undergraduate, or graduate levels - is 5.3.

Students were required to take notes on a 3000-word lecture on the state of the world (as determined by the Global Peace Index) and a 1500-word reading which explained possible causes for and solutions to instability. The students were then required to write a timed essay which integrated understanding of these texts in response to the following question: "Why do you think Thailand's GPI score is so low, and what actions could be taken to improve conditions in the country?" In the essay which follows, the student has used the SPSE structure.

Nowadays, Thai society is getting more dangerous and worse in these recent years. Thailand has been called the "Land of Smiles" for a long period of time (Punyaratabandhu, 2012). However, Thailand also has been recorded as a "flawed democracy", and one of the Asian countries which is at the risk of becoming a failed state (Punyaratabandhu, 2012). The Institute for Economics and Peace has established the program called the Positive Peace Index (PPI), which helps to improve the social's structure in each country all over the world (Punyaratabandhu, 2012). It shows most of the high level of education and low level of corruption is in the Scandinavian countries (Rush, 2012). However, Thailand ranks 66 out of 108 countries, which means that Thailand is one of the most unpeaceful countries in the world, so the Thai government still needs to improve the high level of corruption, and the inequality between rich and poor, well educated and less educated, in Thai society (Punyaratabandhu, 2012).

The most significant problem which has made Thailand become one of the most unpeaceful and undeveloped countries of the world, is the lack of education in rural areas of Thailand and the inequality between rich and poor people (Punyaratabandhu, 2012). About 50\% of Thai children have not graduated from high-school and do not have enough efforts for the national standard (Punyaratabandhu, 2012). These problems are caused by "Thailand's social structure" because most of Thai children in rural areas do not have enough money to go to school. This problem makes more Thai children cannot chase their dreams or pursue that happiness in their lives (Punyaratabandhu, 2012). Furthermore, this shows the inequality between rich and poor people which still exists in the Thai society. People who have enough money can go to school. On the contrary, people who are poor cannot go to school. This situation seems getting worse every day. Moreover, the Thai government always focuses to improve only urban cities such as Bangkok, but they do not concentrate on development in the rural areas of Thailand.

According to Punyaratabandhu (2012), many policies in Thailand have been created by the authority of a rich people which is unfair for poor people. As a result, this situation could lead to another problem such as poor people cannot express their ideas or opinions on what they want and their needs. Since this situation is getting serious, if the Thai government does not stop these problems or figure out the solution as soon as possible, Thailand will not be as a peaceful country as those Scandinavian countries.

To solve the problems, the Thai government should concentrate more on problems in the rural areas because they are the part of Thailand too. One of the popular foundations which helps to improve the education for children all over the world, known as the United Nations Children's Education Fund or the "UNICEF" (Punyaratabandhu, 2012), has been working in Thailand for many years because they want to make sure that Thai schools become "Child-Friendly 
Schools", or CFS. This program has been established for all Thai children in order to give them chances and opportunities equally to study in Thai schools (Punyaratabandhu, 2012). In order to become successful as a peaceful country in the globalized world, Thailand needs to improve the fundamental problems such as the social structure by creating a law to protect all of Thai people, not only rich people, and also it is essential for the Thai government to give an opportunity to poor people to have their freedom or rights to speak for their needs.

UNICEF might be a great idea or plan to reduce the problem of the unequal education for rural areas in Thailand because the UNICEF has been working in many countries around the world for such a long period of time. Therefore, they have their potential to reduce the inequality of the poor children to have their rights for studying. If the Thai government is concentrating about the rural areas' issue, the unpeaceful problem in Thailand will be eliminated as well. As a result, Thai people will live happily, and there will be no more fear about social discrimination again. 


\section{Appendix E}

ICU Writing Rubric

\begin{tabular}{|c|c|c|c|}
\hline & Excellent 3 & Good 2 & Developing 1 \\
\hline \multicolumn{4}{|c|}{ Content: critical / creative thinking } \\
\hline \multicolumn{4}{|l|}{ - sufficient evidence } \\
\hline \multicolumn{4}{|l|}{ - quality of evidence } \\
\hline \multicolumn{4}{|l|}{ - $\operatorname{logic}$} \\
\hline \multicolumn{4}{|l|}{ Organization } \\
\hline \multicolumn{4}{|c|}{ - intro-body-conclusion structure } \\
\hline \multicolumn{4}{|l|}{ - arguable thesis } \\
\hline \multicolumn{4}{|l|}{ - topic sentences } \\
\hline \multicolumn{4}{|c|}{ Language control and convention } \\
\hline \multicolumn{4}{|c|}{ - grammar, word choice, spelling } \\
\hline \multicolumn{4}{|c|}{$\begin{array}{l}\text { - format (margins, spacing, } \\
\text { indentation, font size) }\end{array}$} \\
\hline \multicolumn{4}{|c|}{ - citations and works cited } \\
\hline Total & & & \\
\hline
\end{tabular}

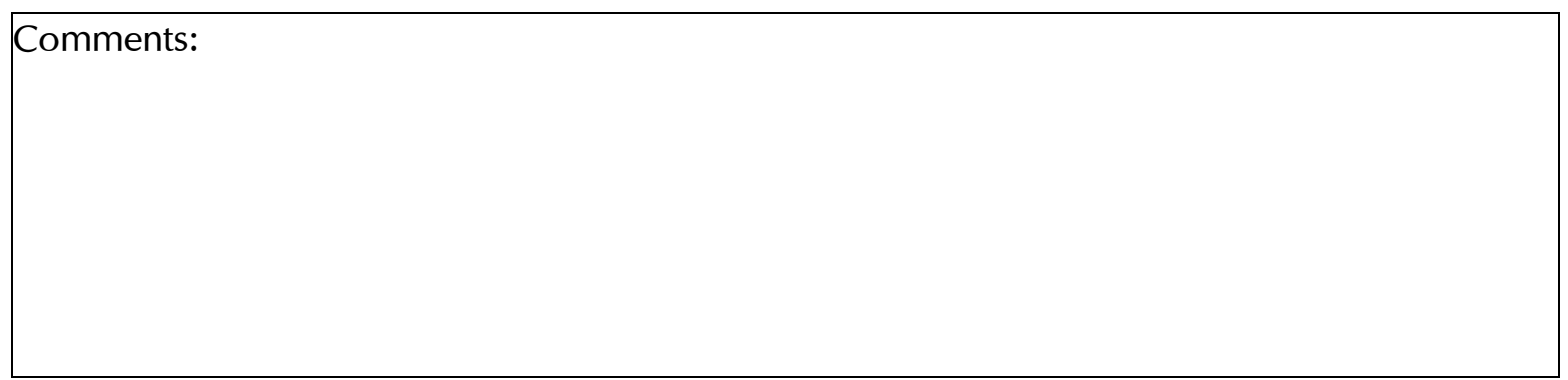

